\title{
Serum insulin-like growth factor binding protein-2 levels as an indicator of functional ability in elderly men
}

\author{
Annewieke W van den Beld ${ }^{1,2}$, Werner F Blum ${ }^{3}$, Huibert A P Pols ${ }^{1}$, Diederick E Grobbee ${ }^{2}$ and \\ Steven W J Lamberts ${ }^{1}$ \\ ${ }^{1}$ Department of Internal Medicine III, Erasmus University, Rotterdam, The Netherlands, ${ }^{2}$ Julius Center for Patient Oriented Research, Utrecht University \\ Hospital, Utrecht, The Netherlands and ${ }^{3}$ Clinical Research Physician Endocrinology, Lilly Deutschland, Bad Homburg, Germany and University Childrens \\ Hospital of Giessen, Germany
}

(Correspondence should be addressed to A W van den Beld, Department of Internal Medicine, Room D4, Erasmus Medical Center, 40 Dr. Molenwaterplein, 3015 GD Rotterdam, The Netherlands; Email: a.vandenbeld@erasmusmc.nl)

\begin{abstract}
Background: In a cross-sectional study in 403 healthy, independently living elderly men (mean age 78 years), we determined which are the main physiological determinants of functional ability in the elderly, and which components of the somatotropic system contribute to the maintenance of functional ability.

Methods: Functional ability was assessed by the number of problems in activities of daily living and by a measure of physical performance. Other physical characteristics included leg extensor strength, bone mineral density of total body and proximal femur, and body composition, including lean mass and fat mass. Serum insulin-like growth factor (IGF)-I and its binding proteins (IGFBP) $-1,-2$ and -3 concentrations were all measured by RIA.

Results: Muscle strength was related to a lower degree of disability. Further, it was positively related to physical performance and bone mineral density (all $P<0.001$ ). Fat mass influenced activities of daily living and physical performance negatively and bone mineral density positively (all $P<0.001$ ). Serum concentrations of IGF-I and IGFBP-3 were not related to any of the physical characteristics. High serum IGFBP-2 concentrations were related to a higher degree of disability $(P<0.001)$, a lower physical performance $(P=0.006)$, muscle strength $(P=0.002)$, bone mineral density of proximal femur $(P=0.007)$, lean mass and fat mass (both $P<0.001)$. Serum insulin and IGFBP1 concentrations were independently, positively related to lean mass $(P=0.003)$ and fat mass $(P<0.001)$.

Conclusions: In independently living elderly men, functional ability appears to be determined by muscle strength (positive) and fat mass (negative). Low serum IGFBP-2 concentrations are a powerful indicator for overall good physical functional status, probably inversely reflecting the integrated sum of nutrition and the biological effects of growth hormone, IGF-I and insulin.
\end{abstract}

European Journal of Endocrinology 148 627-634

\section{Introduction}

There is considerable variation in the effects of aging in healthy individuals, with some persons exhibiting extensive decline in physiological functions with age and others little or none. This suggests that there are usual and successful patterns of aging (1). Genetic factors, lifestyle, and societal investments in a safe and healthful environment are important aspects of successful aging (2). Traditionally, the aging process has been considered to be physiological and unavoidable. Loss of muscle mass and strength are important predictors of a decrease in physical performance (3).
Physical frailty, which is defined as 'a state of reduced physiologic reserves associated with increased susceptibility to disability' (4), frequently occurs towards the end of life and often results in the loss of independence. In recent years it has become evident that it might not be necessary to accept the grim stereotype of aging as an unalterable process of decline and loss $(3,4)$. Prevention of loss of physical functions can be achieved by exercise (3), while hormone replacement with growth hormone $(5-8)$ in the elderly has been demonstrated to improve physical performance in selected groups of elderly individuals. Also, data have recently been reported which suggest that 
the insulin-like growth factor (IGF)/IGF-binding protein (IGFBP) system might be related to the presence or development of prostate malignancies (9).

With regard to the study of the age-related decline of physical function and its relationships with the endocrine system, we investigated two central questions in the present study. First, which are the main physiological determinants of functional ability in the elderly and secondly, which components of the somatotropic system contribute to the maintenance of functional ability. In addition, a possible relationship between prostate disorders and serum concentrations of these hormones was studied. We have investigated these questions in a cross-sectional study in 403 healthy, independently living elderly men.

\section{Subjects and methods}

\section{Subjects}

A cross-sectional, single-center study was conducted in 403 independently living men, aged 70 years and older. Names and addresses of all male inhabitants 70 years and older were drawn from the municipal register of Zoetermeer, a medium-sized town in the mid-western part of the Netherlands. Of a total of 1567 men invited to participate, 886 men did not respond to the mailed invitation in which it was mentioned that only subjects who lived independently and had no severe mobility problems could participate. After exclusion of subjects who did not live independently and subjects who were not physically or mentally able to visit the study center independently, eventually 403 men participated $(25.7 \%)$. The main reason not to participate among the respondents was because they were currently under the care of a medical specialist or general practitioner $(28 \%)$, while $16 \%$ were excluded on the basis of physical $(10 \%)$ or mental $(6 \%)$ problems. Participants signed an informed consent. The study has been approved by the Medical Ethics Committee of the Erasmus University Hospital, Rotterdam. No additional health-related eligibility criteria were used. A number of participants were taking medication for chronic illnesses, including hypertension $(n=96)$ and mild congestive heart failure $(n=28)$. However, in retrospect, none of the medications influenced the relationships described in this study. Some of the illnesses, for example mild knee pain $(n=79)$, influenced the physical characteristics measured, but they did not change the relations between the physical characteristics, nor between the circulating hormone levels and the physical characteristics reported in this study.

\section{Hormone measurements}

Blood samples were collected in the morning after an overnight fast. Serum was separated by centrifugation and was deeply frozen. The period of storage at $-40{ }^{\circ} \mathrm{C}$ varied from 0 to 5 months. Total IGF-I was measured by an IGFBP-blocked radioimmunoassay (RIA) as described previously (10). IGFBP-1, IGFBP-2 and IGFBP-3 were determined by RIA as described previously $(11-13)$. The IGF-I/IGFBP-3 ratio (IGF/BP3) was calculated. Insulin was measured by a commercially available RIA (Pharmacia, Freyburg, Germany).

\section{Physical characteristics}

Physical performance Lower extremity function, or physical performance, was assessed as described by Guralnik et al. (14), including measurements of standing balance, walking speed and ability to rise from a chair. The three tests of standing balance were considered in hierarchical difficulty by assigning a single score of 0 to 4 for standing balance. For the 8-foot walk and repeated chair stands, those who could not complete the task were assigned a score of 0 . Those completing the task were assigned scores of 1 to 4 , corresponding to the quartiles of time needed to complete the task, with the fastest times scored as 4. A summary performance scale was created by summing the category scores for the walking, chairstand, and balance tests, which ranged from 0 (worst performance) to 12 (best performance). Mean scores of the three tests as well as of the summary performance scale measured in this study were comparable to those reported in subjects of the same age group investigated by Guralnik et al. (14).

Activities of daily living (ADL) Self-reported disability or satisfaction in performing activities of daily living was assessed by a self-administered questionnaire modified from the Stanford Health Assessment Questionnaire as described by Pincus et al. (15). A score of 8 points was obtained if the participants reported no problems in activities of daily living, needed no help and when there was no difference compared with the situation 6 months ago. A minimum score of 0 was given if participants improved compared with 6 months previously, while a maximum score of 36 points was assigned to participants who reported severe problems in activities of daily living, needed help and had more problems in activities of daily living compared with 6 months ago. The lower the points measured in this ADL score, the lower the degree of disability.

The Mini-Mental State Exam was used to determine cognitive function (16).

Muscle strength Isometric leg extensor strength was measured as described by Hsieh and Phillips using the Hoggan MicroFET hand-held dynamometer (17). The measurement requires that the participant, in a seated position, pushes the dynamometer, which is held at the tibia preferably $33 \mathrm{~cm}$ below the knee joint, with maximal strength. The investigator holds the dynamometer in the hand with an extended arm 
and pushes back until the breaking point is reached. The measurements were carried out in two positions and on both legs. During the first series of measurements the leg was held in $120^{\circ}$ extension and during the second series of measurements the leg was in an extended position $\left(180^{\circ}\right)$. During the first series of measurements the participant holds a device over the leg tested, which keeps the leg at exactly $120^{\circ}$. The measurements were done three times and the maximum performance at each position was recorded. To obtain one measure of leg muscle strength, 'maximum leg extensor strength' was defined as the maximum strength for the right or left leg in a position of $120^{\circ}$. Statistical analyses were based on the physical unit measurement, moments $(\mathrm{Nm})$, obtained by multiplying the maximum strength (in Newton $(\mathrm{N})$ ) and the distance of the dynamometer to the knee joint (in meters $(\mathrm{m}))$.

Bone mineral density and body composition Total body bone mineral density was measured using dual energy X-ray absorptiometry (DXA, Lunar, Madison, WI, USA), as were hip bone mineral densities at the femoral neck, trochanter and Ward's triangle. In addition, total lean body mass and fat mass were measured $(18,19)$. Quality control, including calibration, was performed routinely every morning for DXA, using the standard provided by the manufacturer.

Height and weight were measured in the standing position without shoes. Body mass index was calculated as the weight in kilograms divided by the square of the height in meters.

Measurements of prostate Medical history of signs of enlarged prostate were obtained. Rectal examination was performed. Prostate-specific antigen (PSA) was determined by a commercially available kit.

\section{Data analyses}

Results are expressed, unless otherwise stated, as means and standard deviation with the interquartile (IQ) range. Variables which were not normally distributed were logarithmically transformed. Relations between variables were assessed using linear regression for continuous variables, stated as linear regression coefficient $(\beta)$ and standard errors. Multiple regression analysis was used to adjust for age and body mass index, as well as to assess the contribution of different independent variables to the dependent variable. Partial correlations between variables were assessed using Pearson's product $r$. Unless otherwise mentioned, all analyses are done after adjustment for age. Analyses were performed using the Stata statistical package (StataCorp. 1997, Stata Statistical Software: release 5.0, Texas, USA).

\section{Results}

Characteristics of the study population are given in Table 1. Mean age of the study population was 77.8 years (standard deviation 3.58 ).

Relationships between age and the different physical characteristics Physical performance, muscle strength, bone mineral density, lean body mass and fat mass all decreased with age (Table 2). With increasing age, more limitations in activities of daily living were reported.

Relationships among the different physical characteristics Relationships among the different physical characteristics, estimated by linear regression analysis, are illustrated in Fig. 1. Subjects that scored better in the physical performance test had significantly less problems in activities of daily living (i.e. a lower disability) and significantly higher bone mineral density (at all sites measured). Muscle strength was positively, independently related to the physical performance score and bone mineral density at all sites measured, while muscle strength and the number of problems in activities of daily living were inversely related.

Table 1 Descriptive data of the study population.

\begin{tabular}{|c|c|c|c|}
\hline & Means & S.D. & IQ-range \\
\hline Age (years) & 77.8 & 3.6 & $75-80$ \\
\hline Body mass index $\left(\mathrm{kg} / \mathrm{m}^{2}\right)$ & 25.5 & 3.0 & $23.3-27.3$ \\
\hline $\begin{array}{l}\text { Physical performance } \\
\text { (points) }\end{array}$ & 8.5 & 2.4 & $7-10$ \\
\hline $\begin{array}{l}\text { Activities of daily living } \\
\text { (points) }\end{array}$ & 10.7 & 4.3 & $8-12$ \\
\hline $\begin{array}{l}\text { Total body bone mineral density } \\
\left(\mathrm{g} / \mathrm{cm}^{2}\right)\end{array}$ & 1.17 & 0.10 & $1.11-1.23$ \\
\hline $\begin{array}{l}\text { Femoral neck bone mineral density } \\
\left(\mathrm{g} / \mathrm{cm}^{2}\right)\end{array}$ & 0.88 & 0.14 & $0.78-0.97$ \\
\hline $\begin{array}{l}\text { Femoral ward bone mineral density } \\
\left(\mathrm{g} / \mathrm{cm}^{2}\right)\end{array}$ & 0.72 & 0.16 & $0.60-0.82$ \\
\hline $\begin{array}{l}\text { Femoral trochanter bone mineral } \\
\text { density }\left(\mathrm{g} / \mathrm{cm}^{2}\right)\end{array}$ & 0.85 & 0.15 & $0.76-0.94$ \\
\hline Total fat mass $(\mathrm{kg})$ & 21.2 & 6.4 & $17.4-24.5$ \\
\hline Total lean mass $(\mathrm{kg})$ & 51.7 & 5.6 & $47.8-55.5$ \\
\hline $\begin{array}{l}\text { Maximum leg extensor } \\
\text { strength }(\mathrm{Nm})\end{array}$ & 103.2 & 20.9 & $89.4-117.1$ \\
\hline
\end{tabular}

Table 2 Relations between physical characteristics and age.

\begin{tabular}{lrcc}
\hline & $\boldsymbol{\beta}$ & \pm S.E. & $\boldsymbol{P}$ \\
\hline Physical performance score (points/year) & $-0.22 \pm 0.03$ & $<0.001$ \\
Activities in daily living (log) (points/year) & $0.01 \pm 0.005$ & 0.02 \\
Total body bone mineral density & $-0.01 \pm 0.001$ & $<0.001$ \\
$\quad\left(\mathrm{~g} / \mathrm{cm}^{2} /\right.$ year) & & & \\
Total fat mass (kg/year) & $-0.18 \pm 0.09$ & 0.05 \\
Total lean mass (kg/year) & $-0.38 \pm 0.08$ & $<0.001$ \\
Maximum leg extensor strength (Nm/year) & $-1.54 \pm 0.28$ & $<0.001$
\end{tabular}

$\beta$ regression coefficient denotes changes in unit per year. For example: Physical performance score decreases 0.22 point per year. 


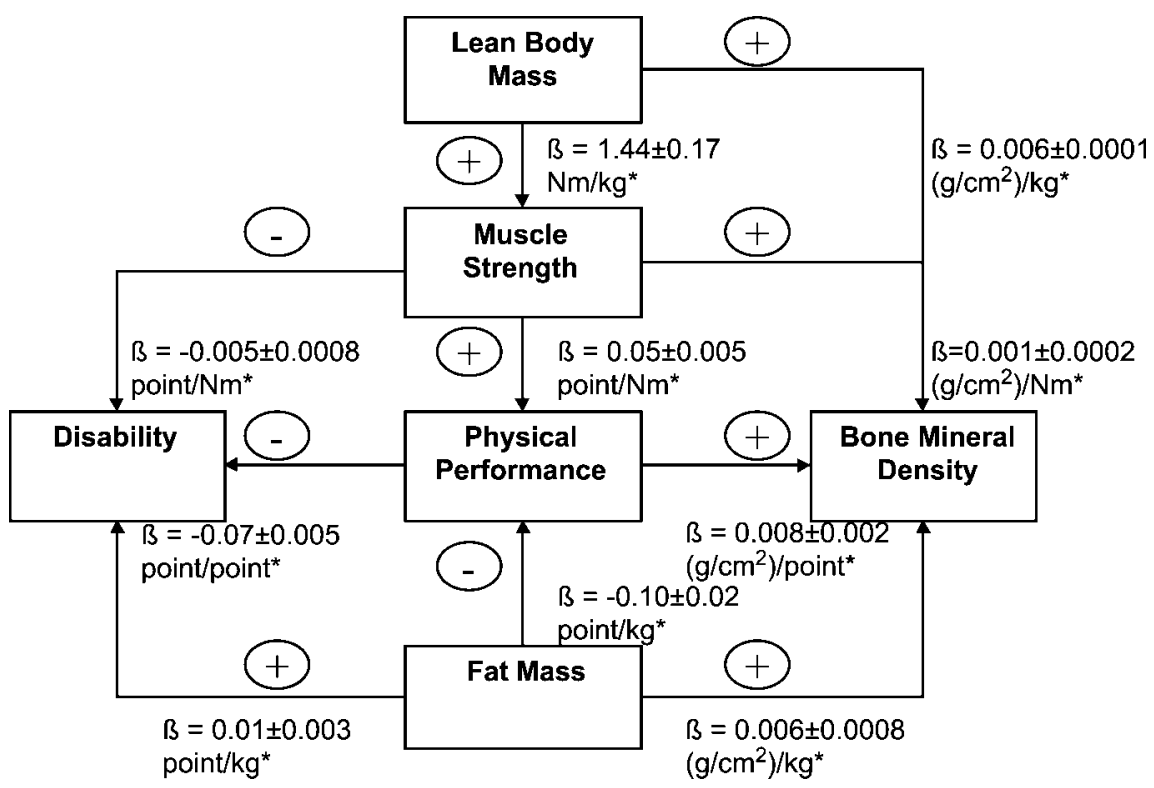

Figure 1 Relationships between the physical characteristics monitored in this study. $\beta$ denotes linear regression coefficient e.g. physical performance increases $0.05 \pm 0.005$ point per $\mathrm{Nm}$ muscle strength. ${ }^{*} P<0.001$. Since physical performance, activities in daily living, bone mineral density and muscle strength were all associated with body mass index, analyses including these parameters were carried out after adjustment for body mass index (and age). Activities of daily living were not normally distributed; therefore activities of daily living were included in the analyses after logarithmic transformation. The linear regression coefficient of the relationship between muscle strength and activities of daily living is negative: the lowest scores in activities of daily living (i.e. few problems) were reported in men with the highest muscle strength. Thus, a higher muscle strength is associated with a better performance in activities of daily living and therefore with less disability. Part of the relationship between physical performance and bone mineral density was explained through muscle strength.

This implies that subjects with high muscle strength reported significantly less problems with activities of daily living (lower disability), scored significantly better in the physical performance test and had significantly higher bone mineral density compared with subjects with low muscle strength. Further, lean body mass was strongly associated with muscle strength.

Fat mass was inversely related to the physical performance score, but independently positive with problems in activities of daily living and total body as well as proximal femur bone mineral density. This implies that subjects with a high fat mass scored significantly lower on the physical performance test, had more problems with activities of daily living, but had significantly higher bone mineral density compared with subjects with low fat mass.

Relations between the hormones and age The summarized values of the hormones are presented in Table 3. Serum concentrations of IGF-I and its binding protein, IGFBP-3, decreased with age $(\beta=$ $-0.85 \pm 0.41(\mu \mathrm{g} / \mathrm{l}) /$ year, $P=0.04$, and $\beta=-0.07 \pm$ $0.01(\mathrm{mg} / \mathrm{l}) /$ year, $P<0.001$ respectively). Serum concentrations of IGFBP-1 and IGFBP-2 increased with age $(\beta=0.03 \pm 0.006(\mu \mathrm{g} / \mathrm{l}) /$ year, $P<0.001$ and $\beta=$ $0.26 \pm 0.04(\mathrm{mg} / \mathrm{l}) /$ year,$P<0.001$ respectively $)$.
Relationships amongst serum somatotropic hormone concentrations Serum IGF-I and IGFBP-3 concentrations were strongly and positively related $(r=0.53, P<0.001)$. Serum IGF-I concentrations were inversely related to those of IGFBP-1 $(r=-0.17, P<0.001)$ and IGFBP-2 $(r=-0.19$, $P<0.001)$. However, as the IGFBP-1 and IGFBP-2 concentrations were interrelated $(r=0.49, \quad P<$ $0.001)$, a multiple regression analysis including IGFBP-1, as well as IGFBP-2, was performed. In this analysis serum IGF-I levels remained related only to those of IGFBP-2. The relationships between serum concentrations of IGFBP-3 and those of IGFBP-1 and IGFBP-2 respectively, were dependent on IGF-I. Insulin concentrations were independently related to those of IGFBP-1 and IGFBP-2 $(r=-0.30$ and $r=-0.28$, $P<0.001$ respectively).

Table 3 Summarized values of serum hormone concentrations.

\begin{tabular}{lccc}
\hline & Mean & s.D. & IQ-range \\
\hline IGF-I $(\mu \mathrm{g} / \mathrm{l})$ & 100.9 & 29.2 & $81.2-118.9$ \\
IGFBP-1 $(\mu \mathrm{g} / \mathrm{l})$ & 31.7 & 15.5 & $21.2-38.6$ \\
IGFBP-2 $(\mathrm{mg} / \mathrm{l})$ & 0.62 & 0.32 & $0.40-0.76$ \\
IGFBP-3 $(\mathrm{mg} / \mathrm{l})$ & 2.59 & 0.70 & $2.09-3.04$ \\
Insulin $(\mathrm{IU} / \mathrm{l})$ & 8.91 & 4.25 & $6.07-10.5$ \\
\hline
\end{tabular}


Serum IGF-I and the binding proteins in relation to physical characteristics Serum IGF-I and IGFBP-3 concentrations were not directly related to any of the physical characteristics studied. In contrast, serum IGFBP-2 levels were significantly, inversely related to virtually all the variables measured including femur bone mineral density, except for total body bone mineral density (Fig. 2). As IGFBP-2 levels were strongly related to body mass index $\left(\beta=-4.00 \pm 0.45\left(\mathrm{~kg} / \mathrm{m}^{2}\right) /(\mathrm{mg} / \mathrm{l})\right.$, $P<0.001)$, all analyses were repeated after adjustment for body mass index (except for lean and fat mass). Physical performance scores decreased 1.13 \pm 0.41 points per $\mathrm{mg} / \mathrm{l}$ increase in IGFBP-2 $(P=0.005)$. Significantly more problems in activities of daily living were reported with increasing serum IGFBP-2 concentrations (log transformed $\beta=0.19 \pm 0.06$ points $/(\mathrm{mg} / \mathrm{l})$, $P<0.001)$. Furthermore, muscle strength decreased $11.33 \pm 3.51 \mathrm{Nm}$ per $\mathrm{mg} / \mathrm{l}$ increase in IGFBP-2 $(P=$ 0.001). Bone mineral density of the neck region decreased $0.07 \pm 0.03 \mathrm{~g} / \mathrm{cm}^{2}$ per $\mathrm{mg} / \mathrm{l}$ increase in IGFBP-2 $(P=0.005)$. In addition, both lean body mass and fat mass were lower in individuals with higher IGFBP-2 concentrations (respectively $\beta=-4.09 \pm$ $0.88 \mathrm{~kg} /(\mathrm{mg} / \mathrm{l})$, and $\beta=-5.58 \pm 0.90 \mathrm{~kg} /(\mathrm{mg} / \mathrm{l})$, both $P<0.001)$. The inverse relationship between IGFBP-2 and physical performance was explained through the inverse relationship between IGFBP-2 and muscle strength. All the other relationships were independent of each other.
Serum IGFBP-1 levels were inversely related to physical performance scores, fat mass and lean body mass, and positively related to problems in activities of daily living. However, serum IGFBP-1 and -2 levels were positively related and the relationships between IGFBP-1 and physical performance and activities in daily living, respectively, were no longer significant after adjustment for IGFBP-2. The relationships between IGFBP-1 and fat mass and lean body mass, respectively, were independent of IGFBP-2 $(\beta=-0.14 \pm 0.02 \mathrm{~kg} /(\mu \mathrm{g} / \mathrm{l})$ and $\beta=-0.09 \pm 0.02 \mathrm{~kg} /(\mu \mathrm{g} / \mathrm{l}), P<0.001$ respectively $)$.

Serum insulin concentrations were positively, and independent of serum IGFBP-1 and IGFBP-2 concentrations, related to lean body mass as well as fat mass $(\beta=0.23 \pm 0.06 \mathrm{~kg} /(\mathrm{IU} / \mathrm{l})$ and $\beta=0.40 \pm$ $0.06 \mathrm{~kg} /(\mathrm{IU} / \mathrm{l}), P<0.001$ respectively $)$.

Relationship between measurements of the IGFsystem and the prostate Subjects with a medical history of an enlarged prostate $(n=120)$ or with an enlarged prostate at palpation $(n=95)$ did not have circulating IGF-I, IGFBP-1, $-2,-3$ and IGF/BP3 ratio concentrations which differed from the other subjects. In addition, subjects with a suspicion of prostate malignancy at palpation $(n=19)$ or a PSA level above $10 \mathrm{ng} / \mathrm{ml}(n=34)$ did not have different IGF-I, IGFBP-1, -2 and -3 concentrations or IGF/BP3 ratio compared with the other subjects. Serum PSA concentrations were also not related to IGF-I, IGFBP-1, -2, -3

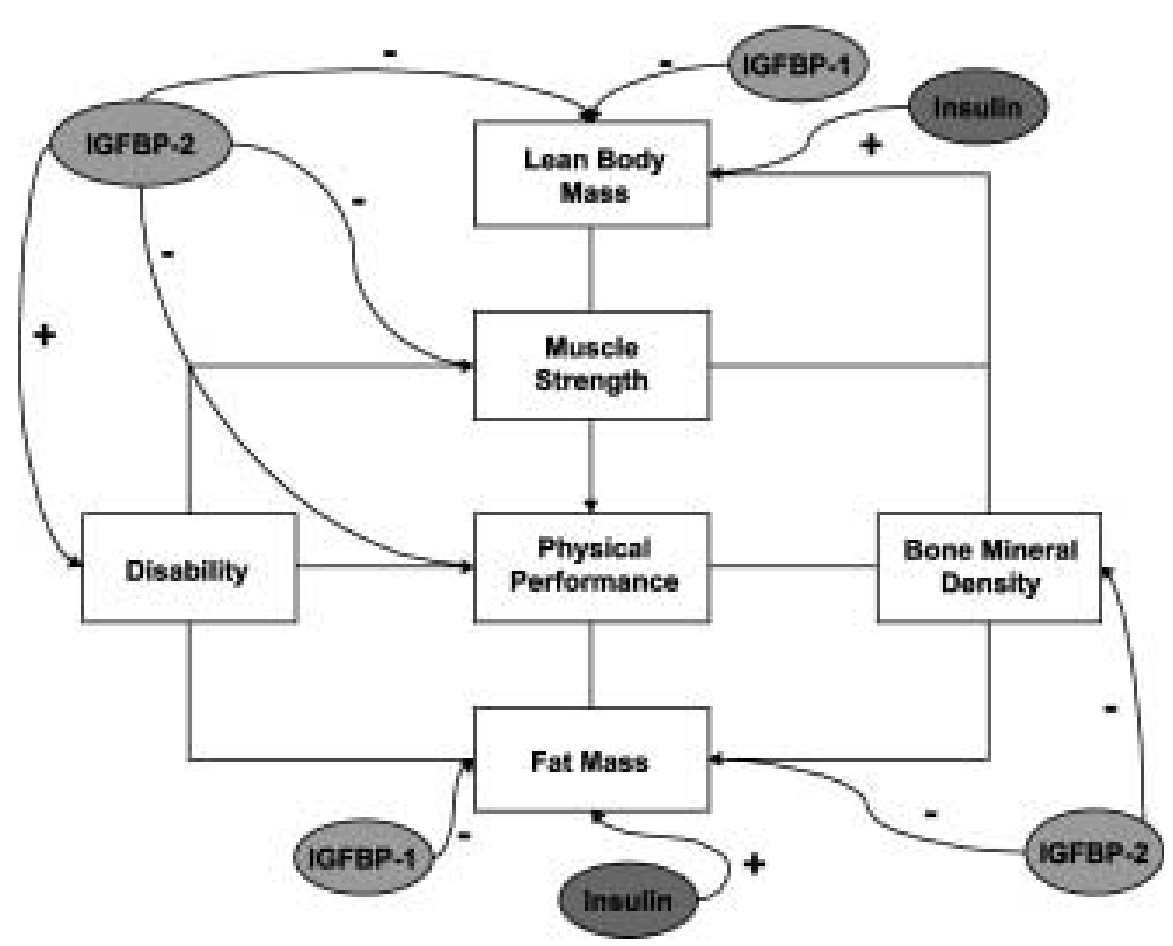

Figure 2 Relationships between serum concentrations of IGFBP-2, IGFBP-1, and insulin with the characteristics of physical function. The effects of all hormones mentioned in this figure were independent of each other. 
and the IGF/BP3 ratio in a linear regression analysis. The proportion of subjects with clinical symptoms of an enlarged prostate, an enlarged prostate at palpation, or PSA levels above $10 \mathrm{ng} / \mathrm{ml}$ was not different in quartiles of IGF-I, IGFBP-1, $-2,-3$ and IGF/BP3 ratio.

The 35 subjects with a malignancy in their medical history did not have serum IGFBP-2 concentrations which differed from those of the other subjects.

\section{Discussion}

To appreciate the findings of this study, some aspects need to be discussed. In evaluating the physical functional status of the elderly, the choice of the best approach to measurement remains uncertain. The main clinical correlate used in this study is functional ability, self-reported as well as objectively assessed as a physical performance score using the approach proposed by Guralnik et al. (14). Guralnik demonstrated that a short battery of performance measures of lower extremity function predicts mortality and loss of independence amongst older persons. In addition, bone mineral density, muscle strength and body composition were measured as physical characteristics. Overall physical function, as well as cognitive function in this group of elderly men were relatively good. Only 30 individuals scored less then 24 points in the mini-mental state exam, which indicates mild cognitive impairment. In less selected populations with a broader range of functional ability associations are likely to be, if anything, stronger.

In the present work two major questions in the study of the age-related decline of physical function were addressed. With regard to the first question asked, our findings in this large population of independently living elderly men suggest that high muscle strength and low fat mass are independent determinants of functional ability. This finding agrees with other studies, which demonstrated that muscle strength is independently and positively related to physical performance $(3,20)$ and to bone mineral density $(21,22)$, and inversely related to the number of problems in activities of daily living. Fat mass, on the other hand, is inversely related to physical performance and restricted activities in daily living, but positively related to bone mineral density. This latter relationship probably reflects the effect of hormones, such as estradiol or insulin, or simply the effects of mechanical loading. These observations, as well as the other significant relationships found in this study, led us to prepare a diagram representing the relationships between activities in daily living, physical performance, bone mineral density, muscle strength and body composition, as summarized in Fig. 1.

Some of the age-related physiological changes may be influenced by the activity of the endocrine system $(23,24)$. In this population, physical function declines with age. In parallel, serum IGF-I and IGFBP-3 concentrations significantly decreased with age, while those of IGFBP-1 and IGFBP-2 increased. With regard to the second question, e.g. which components of the somatotropic system contribute to the maintenance of functional ability, we found no correlation between serum IGF-I or IGFBP-3 concentrations on the one hand and measures of functional ability, muscle strength, bone mass and body composition on the other. This finding agrees with previous reports (25-30). We did, however, demonstrate highly significant inverse relationships between serum IGFBP-2 concentrations and virtually all the physical characteristics measured. IGFBP-2 is present in the human serum in very high concentrations. In adult life, IGFBP-2 probably acts to inhibit the biological effects of IGF-I (31). IGFBP-2 is regulated by several mechanisms. It decreases after birth until puberty, after which it gradually increases again, especially after the age of $60(12,32)$. At age 80 , concentrations are nearly twice as high as in young adults $(0.60 \mathrm{mg} / \mathrm{l}$ vs $0.35 \mathrm{mg} / \mathrm{l})$. Therefore, the decline in functional ability and the increase in serum IGFBP-2 concentrations proceed in parallel. The precise mechanisms regulating IGFBP-2 concentrations remain unclear, although it is recognized that serum IGFBP-2 concentrations are higher during starvation, fasting and protein restriction, as well as in growth hormone deficiency $(33-35)$, while they respond with a decrease during growth hormone treatment $(36,37)$. In this study, serum IGFBP-2 levels were strongly inversely related to serum albumin concentration (data not shown), which is generally regarded as a measure of nutritional status (38). In addition, IGF-I appears to be a regulator of IGFBP-2, since IGF-I administration increases its serum levels (39), possibly, however, via a suppression of growth hormone secretion (40). Finally, insulin has been proposed as a regulator of IGFBP-2, although evidence is not yet clear-cut (41). In this study, serum IGF-I, IGFBP-3 as well as fasting insulin concentrations were all inversely related to IGFBP-2 as well. Insulin, which is considered to be an anabolic hormone, was independent of IGFBP-2, related to fat mass and lean mass only. Low serum IGFBP-2 concentrations seem to be related to an anabolic state and turn out to be a powerful indicator of overall good physical functional status in elderly men. We suggest that serum IGFBP-2 concentrations inversely reflect the integrated sum of the nutritional state, as well as the biological effects of growth hormone, IGF-I, and insulin.

As IGFBP-2 concentrations have been reported to be elevated in patients with several malignant tumors (42, 43), in particular prostate carcinoma (39), one might hypothesize that the association between IGFBP-2 and functional ability is dependent on the presence of prostate malignancies. However, even within the group of individuals with elevated PSA levels, there was no relation between IGFBP-2 and PSA, 
or other prostate abnormalities. Additionally, in agreement with Ho and Baxter, we did not find abnormal IGFBP-2 concentrations in subjects with an enlarged prostate (44). Consequently, from our study, we do not have any indication that IGFBP-2 is produced by the prostate. This implies that the relationships between IGFBP-2 and the physical characteristics are not dependent on the presence of prostate hypertropy or malignancy.

In conclusion, muscle strength and functional ability are considered to be the key characteristics of physical functional status in independently living elderly men. Functional ability appears to be determined by muscle strength (positive) and fat mass (negative). The more marked the functional ability, the higher the bone mineral density. Low serum IGFBP-2 concentrations are a powerful indicator for an overall good physical functional status, probably inversely reflecting the integrated sum of nutritional status as well as of the biological effects of growth hormone, IGF-I and insulin.

\section{Acknowledgements}

We thank Annette Bak for help in initiating the study. Schering Ltd Berlin is thanked for financial support. Dr W Kiess of the University Childrens Hospital in Giessen, Germany is thanked for performing the hormone measurements. Andro Medical Research, Rotterdam facilitated the investigation by offering assistance and the use of its study-center in the city of Zoetermeer. Finally, the cooperation of the city board and the general practitioners of the city of Zoetermeer is acknowledged.

\section{References}

1 Rowe JW \& Kahn RL. Human aging: usual and successful. Science $1987237143-149$.

2 Slemenda CW, Longcope C, Zhou L, Hui SL, Peacock M \& Johnston CC. Sex steroids and bone mass in older men. Positive associations with serum estrogens and negative associations with androgens. Journal of Clinical Investigation $1997 \mathbf{1 0 0}$ 1755-1759.

3 Fiatarone MA, O'Neill EF, Ryan ND, Clements KM, Solares GR, Nelson ME et al. Exercise training and nutritional supplementation for physical frailty in very elderly people [see comments]. New England Journal of Medicine 1994330 1769-1775.

4 Buchner DM \& Wagner EH. Preventing frail health. Clinical Geriatric Medicine $199281-17$.

5 Rosen T, Johannsson G \& Bengtsson BA. Consequences of growth hormone deficiency in adults, and effects of growth hormone replacement therapy. Acta Paediatrica 1994399 (Suppl) 21-24.

6 Rudman D, Feller AG, Nagraj HS, Gergans GA, Lalitha PY, Goldberg AF et al. Effects of human growth hormone in men over 60 years old [see comments]. New England Journal of Medicine 1990 $3231-6$.

7 Papadakis MA, Grady D, Black D, Tierney MJ, Gooding GA, Schambelan $\mathrm{M}$ et al. Growth hormone replacement in healthy older men improves body composition but not functional ability [see comments]. Annals of Internal Medicine $1996 \mathbf{1 2 4} 708$-716.

8 Welle S, Thornton C, Statt M \& McHenry B. Growth hormone increases muscle mass and strength but does not rejuvenate myofibrillar protein synthesis in healthy subjects over 60 years old. Journal of Clinical Endocrinology and Metabolism $1996 \mathbf{8 1}$ 3239-3243.

9 Chan JM, Stampfer MJ, Giovannucci E, Gann PH, Ma J, Wilkinson $\mathrm{P}$ et al. Plasma insulin-like growth factor-I and prostate cancer risk: a prospective study [see comments]. Science $1998 \mathbf{2 7 9}$ 563-566.

10 Blum WF \& Breier BH. Radioimmunoassays for IGFs and IGFBPs. Growth Regulation 19944 (Suppl 1) 11-19.

11 Breier BH, Milsom SR, Blum WF, Schwander J, Gallaher BW \& Gluckman PD. Insulin-like growth factors and their binding proteins in plasma and milk after growth hormone-stimulated galactopoiesis in normally lactating women. Acta Endocrinologica 1993 $129427-435$.

12 Blum WF, Horn N, Kratzsch J, Jorgensen JO, Juul A, Teale D et al. Clinical studies of IGFBP-2 by radioimmunoassay. Growth Regulation 19933 100-104.

13 Blum WF, Ranke MB, Kietzmann K, Gauggel E, Zeisel HJ \& Bierich JR. A specific radioimmunoassay for the growth hormone $(\mathrm{GH})$ dependent somatomedin-binding protein: its use for diagnosis of GH deficiency. Journal of Clinical Endocrinology and Metabolism $1990701292-1298$.

14 Guralnik JM, Seeman TE, Tinetti ME, Nevitt MC \& Berkman LF. Validation and use of performance measures of functioning in a non-disabled older population: MacArthur studies of successful aging. Aging 19946 410-419.

15 Pincus T, Summey JA, Soraci SA Jr, Wallston KA \& Hummon NP. Assessment of patient satisfaction in activities of daily living using a modified Stanford Health Assessment Questionnaire. Arthritis and Rheumatism 198326 1346-1353.

16 Folstein MF, Folstein SE \& McHugh PR. 'Mini-mental state'. A practical method for grading the cognitive state of patients for the clinician. Journal of Psychiatric Research 197512 189-198.

17 Hsieh CY \& Phillips RB. Reliability of manual muscle testing with a computerized dynamometer. Journal of Manipulative Physiology and Therapy $19901372-82$.

18 Gotfredsen A, Jensen J, Borg J \& Christiansen C. Measurement of lean body mass and total body fat using dual photon absorptiometry. Metabolism $19863588-93$.

19 Mazess RB, Barden HS, Bisek JP \& Hanson J. Dual-energy X-ray absorptiometry for total-body and regional bone-mineral and soft-tissue composition. American Journal of Clinical Nutrition 199051 1106-1112.

20 Rantanen T \& Avela J. Leg extension power and walking speed in very old people living independently. Journals of Gerontology. Series A, Biological Sciences and Medical Sciences 199752 M225-M231.

21 Bevier WC, Wiswell RA, Pyka G, Kozak KC, Newhall KM \& Marcus R. Relationship of body composition, muscle strength, and aerobic capacity to bone mineral density in older men and women. Journal of Bone Mineral Research 19894 421-432.

22 Nguyen TV, Kelly PJ, Sambrook PN, Gilbert C, Pocock NA \& Eisman JA. Lifestyle factors and bone density in the elderly: implications for osteoporosis prevention. Journal of Bone Mineral Research 19949 1339-1346.

23 Rudman D \& Shetty KR. Unanswered questions concerning the treatment of hyposomatotropism and hypogonadism in elderly men. Journal of the American Geriatric Society $199442522-527$.

24 Lamberts SW, van den Beld AW \& van der Lely AJ. The endocrinology of aging [see comments]. Science $1997 \mathbf{2 7 8} 419-424$.

25 Boonen S, Lesaffre E, Dequeker J, Aerssens J, Nijs J, Pelemans W et al. Relationship between baseline insulin-like growth factor-I (IGF-I) and femoral bone density in women aged over 70 years: potential implications for the prevention of age-related bone loss. Journal of the American Geriatric Society $1996 \mathbf{4 4}$ 1301-1306.

26 Johansson AG, Forslund A, Hambraeus L, Blum WF \& Ljunghall S. Growth hormone-dependent insulin-like growth factor binding protein is a major determinant of bone mineral density in healthy men. Journal of Bone Mineral Research 19949 915-921. 
27 Erfurth EM, Hagmar LE, Saaf M \& Hall K. Serum levels of insulinlike growth factor I and insulin-like growth factor-binding protein 1 correlate with serum free testosterone and sex hormone binding globulin levels in healthy young and middle-aged men. Clinical Endocrinology $1996 \mathbf{4 4} 659-664$.

28 Rudman D, Drinka PJ, Wilson CR, Mattson DE, Scherman F, Cuisinier MC et al. Relations of endogenous anabolic hormones and physical activity to bone mineral density and lean body mass in elderly men. Clinical Endocrinology 199440 653-661.

29 Goodman-Gruen D \& Barrett-Connor E. Epidemiology of insulinlike growth factor-I in elderly men and women. The Rancho Bernardo Study [published erratum appears in American Journal of Epidemiology 1997146 357] [see comments]. American Journal of Epidemiology $1997 \mathbf{1 4 5}$ 970-976.

30 Papadakis MA, Grady D, Tierney MJ, Black D, Wells L \& Grunfeld C. Insulin-like growth factor 1 and functional status in healthy older men. Journal of the American Geriatric Society 1995 43 1350-1355.

31 Gockerman A, Prevette T, Jones JI \& Clemmons DR. Insulin-like growth factor (IGF)-binding proteins inhibit the smooth muscle cell migration responses to IGF-I and IGF-II. Endocrinology 1995 $1364168-4173$.

32 Schwander J \& Mary JL. The RIA for IGFBP-2 in man - a meagre catch? Growth Regulation 19933 104-108.

33 Counts DR, Gwirtsman H, Carlsson LM, Lesem M \& Cutler GB Jr. The effect of anorexia nervosa and refeeding on growth hormonebinding protein, the insulin-like growth factors (IGFs), and the IGF-binding proteins. Journal of Clinical Endocrinology and Metabolism $199275762-767$.

34 Smith WJ, Underwood LE \& Clemmons DR. Effects of caloric or protein restriction on insulin-like growth factor-I (IGF-I) and IGF-binding proteins in children and adults. Journal of Clinical Endocrinology and Metabolism $199580443-449$.

35 Straus DS \& Takemoto CD. Effect of dietary protein deprivation on insulin-like growth factor (IGF)-I and -II, IGF binding protein-2, and serum albumin gene expression in rat. Endocrinology 1990 127 1849-1860.

36 Clemmons DR, Snyder DK \& Busby WH Jr. Variables controlling the secretion of insulin-like growth factor binding protein-2 in normal human subjects. Journal of Clinical Endocrinology and Metabolism 199173 727-733.
37 Kassem M, Brixen K, Mosekilde L, Blum WF \& Flyvbjerg A. Effects of growth hormone treatment on serum levels of insulin-like growth factors (IGFs) and IGF binding proteins 1-4 in postmenopausal women. Clinical Endocrinology $1998 \mathbf{4 9} 747-756$.

38 Klein $\mathrm{S}$. The myth of serum albumin as a measure of nutritional status. Gastroenterology 199099 1845-1846.

39 Zapf J, Schmid C, Guler HP, Waldvogel M, Hauri C, Futo E et al. Regulation of binding proteins for insulin-like growth factors (IGF) in humans. Increased expression of IGF binding protein 2 during IGF-I treatment of healthy adults and in patients with extrapancreatic tumor hypoglycemia. Journal of Clinical Investigation $199086952-961$.

40 Carroll PV, Umpleby M, Alexander EL, Egel VA, Callison KV, Sonksen $\mathrm{PH}$ et al. Recombinant human insulin-like growth factor-I (rhIGF-I) therapy in adults with type 1 diabetes mellitus: effects on IGFs, IGF-binding proteins, glucose levels and insulin treatment. Clinical Endocrinology 199849 739-746.

41 Strasser-Vogel B, Blum WF, Past R, Kessler U, Hoeflich A, Meiler B et al. Insulin-like growth factor (IGF)-I and -II and IGF-binding proteins-1, -2 , and -3 in children and adolescents with diabetes mellitus: correlation with metabolic control and height attainment. Journal of Clinical Endocrinology and Metabolism $1995 \mathbf{8 0}$ $1207-1213$.

42 Zumkeller W, Schwander J, Mitchell CD, Morrell DJ, Schofield PN \& Preece MA. Insulin-like growth factor (IGF)-I, -II and IGF binding protein-2 (IGFBP-2) in the plasma of children with Wilms' tumour. European Journal of Cancer 199329 1973-1977.

43 Reeve JG, Payne JA \& Bleehen NM. Production of immunoreactive insulin-like growth factor-I (IGF-I) and IGF-I binding proteins by human lung tumours. British Journal of Cancer $1990 \mathbf{6 1}$ 727-731.

44 Ho PJ \& Baxter RC. Insulin-like growth factor-binding protein-2 in patients with prostate carcinoma and benign prostatic hyperplasia. Clinical Endocrinology 199746 333-342.

Received 25 November 2002

Accepted 18 March 2003 